\title{
Lodo de estação de tratamento de esgoto (ETE) e compostagem orgânica em cultivo de mudas nativas: estudo na região dos lagos, RJ - Brasil
}

\author{
Thamylla Rodrigues Coelho '; José Augusto Ferreira da Silva l; Marcelo Vizeu Dias ${ }^{1}$
}

\thamyllacoelho@gmail.com

1. Instituto Federal Fluminense - IFF, Macaé - RJ, Brasil.

Histórico do Artigo:

Recebido em: 19 de dezembro de 2018 Aceito em: 15 de julho de $2019 \quad$ Publicado em: 30 de agosto de 2019

Resumo: 0 lodo proveniente do tratamento de esgotos é um problema ambiental decorrente de um crescente aumento do volume resultante do tratamento. A disposição do resíduo na agricultura é permitida, graças aos efeitos positivos demonstrados nas pesquisas, em conjunto com procedimentos dispostos pelo Poder Público para seu gerenciamento. 0 emprego do lodo de esgoto não deve ser referenciado apenas economicamente, uma vez que os ganhos ambientais, agrícolas e sociais são imensuráveis. Buscou-se com a pesquisa realizar uma revisão da literatura sobre a viabilidade de utilização do lodo de esgoto como insumo para composto orgânico na produção de mudas nativas no contexto da realidade da Região dos Lagos no estado do Rio de Janeiro. 0 estudo bibliométrico prima por qualidade, abrangência e significância na busca de informações, logo foram destacadas na revisão, os pontos principais para o emprego do lodo, limitações, benefícios, sua importância como ferramenta de auxílio na recuperação de áreas degradadas e substrato florestal, além das experiências bem-sucedidas em diferentes formas de reciclagem. Com a pesquisa foi possível avaliar a viabilidade na utilização do lodo de esgoto como insumo para produção de composto orgânico com a finalidade de produção de mudas nativas.

Palavras-chave: Sustentabilidade, adubo orgânico, biossólido, Mata Atlântica.

\section{Waste sewage treatment stage sludge (ETE) and organic composting in the cultivation of native changes: study in the region of lagos RJ - Brazil}

\begin{abstract}
Sludge from sewage treatment is an environmental problem due to an increasing volume of treatment. The disposal of the residue in agriculture is allowed, thanks to the positive effects demonstrated in the research, in conjunction with procedures arranged by the Public Power for its management. The use of sewage sludge should not be referred to only economically, since environmental, agricultural and social gains are immeasurable. The research was carried out to review the literature on the feasibility of using sewage sludge as an input for organic compost in the production of native seedlings in the context of the reality of the Lakes Region in the state of Rio de Janeiro. The bibliometric study was based on quality, comprehensiveness and significance in the search for information. The main points for the use of sludge, limitations, benefits and their importance as a tool for the recovery of degraded areas and forest substrate were highlighted in the review. Successful experiences in different forms of recycling. With the research it was possible to evaluate the feasibility of the use of sewage sludge as an input for the production of organic compost for the purpose of producing native seedlings.
\end{abstract}

Keywords: Sustainability, organic fertilizer, biosolids, Atlantic Forest. 
Lodo de estação de tratamento de esgoto (ETE) e compostagem orgânica em cultivo de mudas nativas: estudo na região dos lagos, RJ - Brasil

\title{
Lodo de estación de tratamiento de esgoto (ete) y compostagen orgánica en cultivo de cambios nativos: estudio en la región de los lagos RJ - Brasil
}

\begin{abstract}
Resumen: El lodo del tratamiento de aguas residuales es un problema ambiental debido a un volumen creciente de tratamiento. La eliminación del residuo en la agricultura está permitida, gracias a los efectos positivos demostrados en la investigación, junto con los procedimientos establecidos por el Poder Público para su gestión. El uso de lodos de alcantarillado no debe referirse solo económicamente, ya que las ganancias ambientales, agrícolas y sociales son inconmensurables. La investigación se llevó a cabo para revisar la literatura sobre la viabilidad del uso de lodos de alcantarillado como insumo para el compost orgánico en la producción de plántulas nativas en el contexto de la realidad de la Región de los Lagos en el estado de Río de Janeiro. El estudio bibliométrico se basó en la calidad, la exhaustividad y la importancia en la búsqueda de información. Los puntos principales para el uso de lodos, limitaciones, beneficios y su importancia como herramienta para la recuperación de áreas degradadas y el sustrato forestal se destacaron en la revisión. Experiencias exitosas en diferentes formas de reciclaje. Con la investigación fue posible evaluar la viabilidad del uso de lodos de aguas residuales como insumo para la producción de compost orgánico con el fin de producir plántulas nativas.

Palabras clave: Sostenibilidad, abono orgánico, biosólido, Mata Atlântica.
\end{abstract}

\section{INTRODUÇ̃̃o}

A preocupação em relação ao destino dos efluentes, seu reuso e suas consequências sobre o meio ambiente geram estudos referentes ao tratamento de contaminantes e uma disposição final sustentável de modo a assegurar seu emprego. 0 lodo de esgoto, se reutilizado, é capaz de aumentar a produtividade das culturas, diminuir a dependência de adubos químicos e minerais, e possibilitar sua conversão em energia (elétrica, biogás, biocombustíveis).

Com aproximadamente 97-98\% de água, o lodo "bruto" pode ser definido como o excedente sólido ou semissólido do tratamento de águas residuais, sendo uma mistura com: água, matéria orgânica, resíduos alimentares, micro-organismos (incluindo patógenos) e contaminantes tóxicos, produtos farmacêuticos, sais solúveis, metais e vários elementos químicos (KACPRZAK et al., 2017; FIJALKOWSKI et al., 2017; LIU, 2016).

A destinação na agricultura é uma das alternativas, com a recuperação de áreas degradadas e composição de substratos florestais. A agricultura sustentável promove a recirculação de nutrientes vegetais e as novas tecnologias permitem uma reciclagem completa com redução do risco associado à presença de poluentes (SIQUEIRA et al., 2017; KIRCHMANN et al., 2017; KACPRZAK et al., 2017).

A geração de lodo aumenta gradativamente e requisita uma preocupação ambiental, tanto pela qualidade do efluente tratado quanto ao gerenciamento de forma correta de seu reprocessamento, para que seja possível o uso de energia ou reciclagem orgânica (KACPRZAK et al., 2017). 
Cada estação possui um tipo característico de tratamento, de acordo com sua origem, metodologia de tratamento empregado, condições de armazenamento. Na Região dos Lagos, por exemplo, existem Estações de Tratamento de Esgoto como, por exemplo: ETE de Cabo Frio I, com 30\% e ETE Saquarema e ETE Ponte dos Leites, com aproximadamente 92\% de eficiência, que consiste na retirada de matéria orgânica e nutrientes do efluente (DOMINGUEZ, 2014; ANA, 2017).

A Região dos Lagos conta com o gerenciamento do tratamento de esgoto pela concessionária Prolagos: duas estações em Cabo Frio, uma em São Pedro da Aldeia, uma em Búzios, duas em Arraial do Cabo e uma em Iguaba Grande. Juntas, tratam-se mais de 70 milhões de L/dia de esgoto. Araruama, Saquarema e Silva Jardim são gerenciadas pela Águas de Juturnaíba, com seis ETEs totalizando um tratamento de $297 \mathrm{~L} / \mathrm{s}$ e atendendo aproximadamente 209.520 pessoas (PROLAG0S, 2018; ÁGUAS, 2018).

Com uma produção significativa de lodo de esgoto, a reciclagem agrícola aparenta ser uma destinação promissora, tanto sob o aspecto ambiental, quanto econômico, pois transforma o rejeito em um importante insumo (SIQUEIRA et al., 2017). Isto posto, buscou-se com a pesquisa realizar uma revisão da literatura sobre a viabilidade de utilização do lodo de esgoto como insumo para composto orgânico na produção de mudas nativas no contexto da realidade da Região dos Lagos no estado do Rio de Janeiro.

\section{MATERIAL E MÉTODOS}

A pesquisa está baseada nos métodos exploratório-descritivo com revisão da literatura nas temáticas de higienização do lodo de esgoto por meio da compostagem orgânica. Buscouse avaliar publicações que descrevessem de forma satisfatória o "estado da arte" das principais pesquisas em torno do tema, primando pela qualidade, abrangência das pesquisas por mineração bibliométrica. A busca pelas publicações de interesse foi localizada por meio de consultas na base de dados do periódico CAPES, sendo considerados os trabalhos publicados do ano de 2013 até o ano de 2017. Os motores de busca estão esquematizados na tabela 1.

Tabela 1 - Estrutura dos motores de busca para composição do referencial teórico.

\begin{tabular}{cc}
\hline Motores de busca em inglês & Motores em português \\
\hline (sewage sludge) AND (sustainable final & (lodo de esgoto) AND (destino final \\
destination) AND agriculture & sustentável) AND agricultura
\end{tabular}


Lodo de estação de tratamento de esgoto (ETE) e compostagem orgânica em cultivo de mudas nativas: estudo na região dos lagos, RJ - Brasil

(sewage sludge) AND nutrients AND

(organic matter) AND pathogens AND

(heavy metals) AND agriculture

(sewage sludge) AND (sewage biogas) AND

(gas fuel) AND Biogas AND (power generation)

(sewage sludge) AND nutrients AND

(organic matter) AND (native plants) (lodo de esgoto) AND nutrientes AND

(matéria orgânica) AND patógenos AND

(metais pesados) AND agricultura

(lodo de esgoto) AND (biogás de esgoto) AND (combustível de gás) AND biogás AND (geração de energia)

(lodo de esgoto) AND nutrientes AND

(matéria orgânica) AND (plantas nativas)

Fonte: 0s autores, 2018.

A montagem da tabela consistiu na determinação dos conceitos básicos que deveriam ser explorados pela pesquisa, levando em conta, o contexto, o problema da pesquisa e seus conceitos-chave. As palavras-chave selecionadas foram ligadas ao Operadores Lógicos Booleanos “AND” e "OR" para determinar restrições e amplitudes da abordagem temática. Na sequência foram avaliados os resumos localizados, para uma seleção dos assuntos de maior interesse para a pesquisa, de forma a atender tópicos pertinentes a revisão literária (nos debates teóricos-conceituais e legislação) além de visita técnica na estação de tratamento de esgotos ecológica, localizada em Araruama - RJ.

\section{RESULTADOS E DISCUSSÃ0}

Com a pesquisa bibliométrica pode-se avaliar um bom volume de artigos que debatem tema do lodo de esgoto, em inglês sewage sludge. 0s estudos sobre o tema são realizados em vários países do mundo, de modo a demonstrar que a pesquisa em busca de uma destinação sustentável do composto, em relação à agricultura e melhoria do potencial na produção de energia, combustível, biogás, entre outros, é de suma importância no contexto da reciclagem.

\section{Patógenos}

0 lodo de esgoto conta com vários grandes grupos de bactérias e patógenos, e algumas pesquisas discutem sobre a sobrevivência dos patógenos com alteração do pH, temperatura, predação e competição (KACPRZAK et al., 2017). Bonini et al. (2015) avaliaram a influência do lodo de esgoto e adubação mineral na recuperação de um Latossolo Vermelho degradado com o lodo obtido da SANEAR, no município de Araçatuba - SP, e obtiveram a seguinte análise parasitológica do lodo (Tabela 2). 
Tabela 2 -Análise parasitológica do lodo de esgoto.

\begin{tabular}{|c|c|c|c|}
\hline \multirow{2}{*}{ Helmintos } & \multicolumn{2}{|c|}{ Média } & \multirow{2}{*}{ Total } \\
\hline & Viáveis & Inviáveis & \\
\hline Ascaris sp. & 0,04 & 0,16 & \\
\hline Trchuris sp. & & 0,24 & \\
\hline Toxocara sp. & & 0,08 & \\
\hline Trichuroidea & & 0,04 & \\
\hline Hymenolepis diminuta & & 0,12 & \\
\hline Total & 0,04 & 0,64 & 0,68 \\
\hline$\%$ viabilidade & & & \\
\hline Observação & \multicolumn{3}{|c|}{ Cistos de protozoários $=0,04$} \\
\hline
\end{tabular}

Fonte: Bonini et al. (2015).

Rossmann et al. (2014), por exemplo, recomendam o quantitativo dos ovos de helmintos como um fator indicativo de condições sanitárias, dado sua maior capacidade de sobrevivência e afirmam, ainda, que a elevação do pH provoca alterações significativas, além de produzir um ambiente adverso para a permanência de patógenos.

Portanto, anterior à inserção do lodo na composição de substratos para plantio, devem ser considerados os critérios de qualidade na precaução de contaminantes e poluentes perigosos para a saúde humana e o meio ambiente, o que mostra a importância de desenvolvimento de tecnologia e novas técnicas de análises que colaborem na identificação de contaminantes (KACPRZAK et al., 2017; FIJALKOWSKI, et. al., 2017).

\section{Metais}

Os metais representam o ponto fraco no cenário de reciclagem do lodo no solo de forma direta. Os contaminantes inorgânicos não são biodegradáveis e, portanto, podem acumular-se no solo, entrar na cadeia alimentar, causar lesões fisiológicas às plantas, além de colocar em risco à saúde humana (LIU, 2016; FIJALKOWSKI et al., 2017).

Pathak et al. (2009) afirma que os metais mais comumente encontrados no lodo de esgoto são o: chumbo $(\mathrm{Pb})$, cádmio $(\mathrm{Cd})$, níquel $(\mathrm{Ni})$, cromo $(\mathrm{Cr})$, cobre $(\mathrm{Cu})$ e zinco $(\mathrm{Zn})$ (apud CAMARG0 et al., 2016) e Fijalkowski et al. (2017) acrescenta o manganês (Mn), ferro (Fe), cobalto (Co), mercúrio (Hg), estanho (Sn), molibdênio (Mo) e vanádio (V), que podem ocorrer em diferentes concentrações, dependendo do pH, umidade, quantidade de matéria orgânica, e suas interações com outros elementos. 
Lodo de estação de tratamento de esgoto (ETE) e compostagem orgânica em cultivo de mudas nativas: estudo na região dos lagos, RJ - Brasil

De acordo com a legislação, se o metal ultrapassa os limites estabelecidos, o destino do lodo é a incineração ou o aterro, ao invés de ser reutilizado (LIU, 2016). Bonini et al. (2015) realizaram análise do lodo (Tabela 3) utilizado em seu trabalho no laboratório de Microbiologia da Universidade Federal do Paraná (UFPR).

Tabela 3 - Metais - Ensaio na massa bruta.

\begin{tabular}{|c|c|c|c|}
\hline Parâmetro & Unidade & Resultado & Limite máximo \\
\hline Arsênio & $\mathrm{mg} / \mathrm{kg}$ & $\mathrm{Nd}$ & 1000 \\
\hline Berilio & $\mathrm{mg} / \mathrm{kg}$ & $\mathrm{Nd}$ & 100 \\
\hline Chumbo & $\mathrm{mg} / \mathrm{kg}$ & 0,97 & 100 \\
\hline Cianeto & $\mathrm{mg} / \mathrm{kg}$ & $\mathrm{Nd}$ & 1000 \\
\hline Cromohexavalente & $\mathrm{mg} / \mathrm{kg}$ & 2 & 100 \\
\hline Fenol & $\mathrm{mg} / \mathrm{kg}$ & $\mathrm{Nd}$ & 10 \\
\hline Óleos e graxas & $\mathrm{mg} / \mathrm{kg}$ & 1,3 & - \\
\hline Mercúrio & $\mathrm{mg} / \mathrm{kg}$ & $\mathrm{Nd}$ & 100 \\
\hline Selênio & $\mathrm{mg} / \mathrm{kg}$ & $\mathrm{Nd}$ & 100 \\
\hline Vanádio & $\mathrm{mg} / \mathrm{kg}$ & $\mathrm{Nd}$ & 1000 \\
\hline
\end{tabular}

Fonte: Bonini et al. 2015.

Sampaio et al. (2016) avaliaram o potencial de absorção e mobilização de metais no perfil do solo da Mata Atlântica no primeiro ano após a aplicação de biossólidos municipais, e mostrou que a contaminação parece ser irrelevante até a aplicação de $20 \mathrm{mg}$ ha-1, de forma a comprovar que biossólidos podem ser utilizados de maneira ambientalmente segura sem que os metais se tornem biodisponíveis.

0 aumento no teor de matéria orgânica ao realizar metodologias, como a compostagem, pode restringir a disponibilidade dos metais pesados às plantas. Os métodos biológicos são promissores na remoção dos metais, porém exigem elaboração de técnicas ambientalmente e economicamente satisfatória, e um monitoramento em longo prazo é indispensável para verificar os quantitativos dos metais pesados no solo e controlar seus efeitos no solo (LIU, 2016; CAMARG0 et al., 2016).

\section{Uso sustentável}

A solução para a demanda global por energia e matéria orgânica está no emprego dos resíduos orgânicos, diversificação dos combustíveis e produção de energia limpa e renovável, todas sendo formas de controle do aumento do volume de lodo (SYED et al., 2017; KACPRZAK et al., 2017). Grando et al. (2017) afirmam que a digestão anaeróbica na produção de biogás 
constitui hoje em uma forma sustentável de uso da biomassa, com recuperação de nutrientes e redução das emissões de gases estufa.

No Brasil, alguns estados se sobressaem na questão da destinação do lodo de esgoto para a agricultura, como a Companhia de Saneamento do Paraná (SANEPAR) com produção estimada de 15.680 toneladas de lodo ao ano (LEITE, 2015), e a Companhia Ambiental do Estado de São Paulo (CETESB), as quais possuem manuais técnicos sobre o uso e manejo adequado do lodo de esgoto em cada etapa do processo.

No Brasil, a parceria entre o Governo do Estado, a EMATER e a Companhia de Saneamento de Maringá-PR promovem o reúso agrícola do lodo, com a distribuição do composto higienizado para vários projetos agronômicos. 0s agricultores destacam que o uso do lodo propicia o aumento de produtividade, redução do custo de produção, melhora na qualidade do solo, uniformidade de produção e aumento de lucro (GLOBONEWS, 2018).

Sampaio (2013) apresenta algumas informações sobre a quantidade de lodo utilizada na agricultura no Brasil (Tabela 4). No estado do Rio de Janeiro não há qualquer normativa para o tratamento e destinação agrícola do lodo de esgoto, ou seja, resguardado somente pela Resolução nº. 375/2006 do CONAMA (BRASIL, 2006c).

Tabela 4 - Quantidade de lodo utilizado para fins agrícolas no Brasil, em 2013.

\begin{tabular}{|l|l|l|l|}
\hline \multirow{2}{*}{ Local } & Quantidade & $\begin{array}{l}\text { Teor de } \\
\text { Sólidos }\end{array}$ & Quantidade \\
\cline { 2 - 5 } & Toneladas/ano & $\mathbf{\%}$ & $\begin{array}{l}\text { Toneladas de } \\
\text { matéria seca/ano }\end{array}$ \\
\cline { 2 - 5 } & & 15 & 3.745 \\
Distrito Federal & 24.966 & 27,5 & 4.510 \\
São Paulo (Franca) & 16.400 & 18 & 3.942 \\
São Paulo (Jundiaí) & 21.900 & 20 & 949 \\
Rio Grande do Sul (Santa Maria) & 4.745 & 30 & 7.920 \\
Paraná & 26.400 & & 21.066 \\
\hline Total & 94.411 & \multicolumn{3}{l}{} \\
\hline
\end{tabular}

Fonte: Sampaio, 2013.

A SABESP, em Franca-SP, possui um projeto que transforma o lodo de esgoto em combustível. 0 metano puro, resultante do processo de decomposição e filtragem, pode ser utilizado da mesma forma que o $\mathrm{GNV}$, pois a tecnologia é a mesma. Dessa forma, tem uma 
Lodo de estação de tratamento de esgoto (ETE) e compostagem orgânica em cultivo de mudas nativas: estudo na região dos lagos, RJ - Brasil

economia 1.500 litros de gasolina por dia, pois alimenta os carros de sua frota com 0 biometano que produz (GLOBONEWS, 2018).

Em Curitiba (PR), uma parceria-público-privada (PPP) resultou em uma Unidade de Tratamento de Esgoto que transforma lodo de esgoto em energia elétrica. 0 lodo de esgoto e restos de alimentos são misturados na biodigestão, e convertidos em biogás. A economia de energia elétrica supera um milhão de reais por ano, e a unidade tem a capacidade de produção de cerca de 2,8 Megawatts de energia, correspondente ao consumo de duas mil casas populares (GLOBONEWS, 2018).

As estratégias de um gerenciamento sustentável devem incluir a análise do mercado, a escolha do tratamento de acordo com as condições locais, e uma avaliação dos benefícios e obstáculos. É imprescindível a obrigação de identificar as regiões de maior potencial, aprofundar os estudos logísticos, e apurar a viabilidade de transporte, principalmente se a escolha for o emprego agrícola do lodo (LOMBARDI et al., 2017; ABREU et al., 2017).

\section{Base Legal e Conceitos Norteadores}

A crescente implantação de alternativas para a reciclagem do resíduo formado na fertilização orgânica (MORETTI et al., 2015), demonstra a carência de legislações específicas para regulamentar e orientar o uso agrícola do lodo, de forma a certificar a segurança ambiental e sanitária no gerenciamento, uma vez que não há uma lei própria sobre o tópico lodo de esgoto no Brasil.

A NBR 10.004 (ABNT, 2004) classifica os resíduos sólidos de acordo com o processo ou atividade, e o lodo de esgoto constitui um significativo potencial danoso, por apresentar diversos atributos perigosos, que demonstram que o resíduo deve ser tratado e descartado adequadamente.

No Brasil, a Política Nacional de Resíduos Sólidos, Lei 12.305/2010, é a lei mais recente regulando a disposição de resíduos sólidos (BRASIL, 2010) e sua definição inclui-se o lodo de esgoto, mas não o aborda de forma específica. A Resolução nº 375/2006 do Conselho Nacional do Meio Ambiente - CONAMA prescreve critérios e estratégias para o uso agrícola do lodo de esgoto (BRASIL, 2006c).

A resolução $\mathrm{n}^{0} 375$ disserta exclusivamente sobre o uso do lodo e seus produtos derivados na agricultura, com o objetivo de alcançar os benefícios agrícolas no emprego, de forma a evitar riscos à saúde e ao meio ambiente. A norma proíbe o uso do lodo em pastagens, olerícolas, tubérculos, raízes e culturas inundadas, ou qualquer cultura em que a parte comestível entre em contato com o solo (BRASIL, 2006c). 
0 anexo I da Resolução (BRASIL, 2006c) disserta sobre os processos obrigatórios para redução dos agentes patogênicos, reduzir a atratividade de vetores e a disseminação de doenças. 0 documento inclui restrições a respeito das áreas de aplicação, como em: Áreas de Proteção Ambiental - APA, Área de Preservação Permanente - APP, Áreas de Proteção aos Mananciais - APMs, e assim por diante (BRASIL, 2006c).

Existem vários decretos e normativas que se enquadram ao lodo de esgoto. A produção, a compra, a venda, a cessão, o empréstimo ou a permuta do lodo de esgoto e seus derivados seguem o Decreto no 4.954, de 14 de janeiro de 2004 (BRASIL, 2004), no qual regulamenta a Lei $\mathrm{n}^{\circ}$ 6.894, de 16 de dezembro de 1980, que dispõe a respeito do comércio de fertilizantes, corretivos e outros produtos destinados à agricultura (BRASIL, 1980), com a finalidade de minimizar os riscos.

A Instrução Normativa (IN) No 23, de 31 de agosto de 2005 (BRASIL, 2005), aprova sobre questões de registro, embalagem e a rotulagem dos produtos a base de lodo de esgoto, proveniente do sistema de tratamento de esgotos sanitários, sendo classificado como composto Classe D. A IN 27 (BRASIL, 2006a) aponta as concentrações máximas admitidas sobre agentes fitotóxicos, patogênicos, metais, e, sobre os produtos produzidos, importados ou comercializados. A IN 35 (BRASIL, 2006b) destaca a apresentação no rótulo do produto os cuidados com manuseio, especificando utilização de equipamentos mecanizados e uso EPI.

Nos EUA, Canadá, Austrália e Nova Zelândia, os biossólidos tratados são amplamente utilizados em solos, no entanto, a incineração tem sido sugerida como uma alternativa promissora de disposição final. 0 uso de lodo de esgoto na agricultura varia entre países, na França, Espanha e Reino Unido, por exemplo, a aplicação no solo é amplamente utilizada, a incineração nos Países Baixos e na Suíça, e o aterro na Grécia, Malta e Romênia (FIJALKOWSKI et al., 2017; KIRCHMANN et al., 2017).

\section{Composição dos Biossólidos de ETE e Resíduos Orgânicos}

A verificação e a mensuração da composição dos biossólidos e dos resíduos orgânicos é, dessa forma, etapa primordial no entendimento da relação entre os elementos carbono, nitrogênio e fósforo após aplicação no campo ou na estruturação da formulação de um substrato, de forma a contribuir de forma precisa na agricultura e, ou na produção de mudas florestais, como fonte de nutrientes para as plantas e de matéria orgânica para o solo.

Rossmann et al. (2014) ressaltam que a aplicação do lodo no solo aumenta a absorção de nutrientes e ganho de produtividade. Camargo et al. (2013) afirmam que o biossólido possui 
Lodo de estação de tratamento de esgoto (ETE) e compostagem orgânica em cultivo de mudas nativas: estudo na região dos lagos, RJ - Brasil

potencial como fonte de matéria orgânica e de nutrientes e contribuem nos teores de nitrogênio, enxofre e micronutrientes foliares. Lousada (2015) reconhece que, além do aumento de pH, saturação por bases, capacidade de troca catiônica, fósforo e cálcio, a aplicação do lodo viabiliza acréscimos na macroporosidade, porosidade total, aeração do solo e maior retenção de água no solo.

Avila et al. (2016) avaliaram o lodo de esgoto no cultivo de capim-limão, e demonstraram que o aumento do nitrogênio influenciou positivamente na produção de ramos, biomassa, teores de clorofila, rendimento e teor do óleo essencial. Leite (2015) afirma que o potássio, em quantidades modestas no lodo de esgoto, pode apresentar seus teores corrigidos, na adição de resíduos estruturantes vegetais, como o bagaço de cana e podas urbanas.

Camargo et al. (2013) salientam que pode ocorrer resultados conflitantes em relação à acumulação de nutrientes em tecidos de plantas em função da aplicação de lodo de esgoto, entretanto, deve-se considerar a possibilidade de influência de vários fatores como a composição química do lodo, o período de aplicação, as coletas do material para as análises, as características da espécie vegetal estudada e as várias interações externas.

Paixão Filho et al. (2014) realizaram um estudo sobre a aplicação do lodo pertencente à ETE da cidade de Coronel Macedo - São Paulo, em roseiras e realizaram sua caracterização (Tabela 5), que indica elementos essenciais para uso agrícola (matéria orgânica, nitrogênio, fósforo, potássio, cálcio, magnésio, enxofre), além de estar em conformidade com as regras de uso agrícola estabelecidas pelo CONAMA n ${ }^{\circ}$ 375/2006.

Tabela 5 - Caracterização do lodo de ETE da cidade de Coronel Macedo - SP.

\begin{tabular}{|c|c|c|c|}
\hline Parâmetros & Resultados (base seca) & Parâmetros & $\begin{array}{l}\text { Resultados (base } \\
\text { seca) }\end{array}$ \\
\hline Umidade $(\% \mathrm{v} / \mathrm{v})$ & 70.9 & Cobre $\left(\mathrm{mg} \cdot \mathrm{kg}^{-1}\right)$ & 84.4 \\
\hline $\mathrm{pH}$ & 8.1 & Cromo (mg.kg $\left.{ }^{-1}\right)$ & 26.4 \\
\hline Sólidos Voláteis (\% v/v) & 5.9 & Enxofre $\left(\mathrm{g} \cdot \mathrm{kg}^{-1}\right)$ & 10.3 \\
\hline Sólidos Totais (\% v/v) & 29.1 & Ferro (mg.kg-1) & 19407 \\
\hline Matéria Orgânica (g.kg ${ }^{-1}$ ) & 131 & Fósforo $\left(\mathrm{g} \cdot \mathrm{kg}^{-1}\right)$ & 3.7 \\
\hline Nitrogênio amoniacal (mg.kg-1) & 955 & Magnésio (g. $\left.\mathrm{kg}^{-1}\right)$ & 0.86 \\
\hline Nitrato - Nitrito (mg.kg-1) & 39.5 & Manganês (mg.kg-1) & 180 \\
\hline Nitrogênio Total $\left(\mathrm{g} \cdot \mathrm{kg}^{-1}\right)$ & 14.2 & Mercúrio (mg.kg-1) & $<1.0$ \\
\hline Alumínio (mg.kg-1) & 12175 & Molibdênio (mg.kg-1) & 0.8 \\
\hline Arsênio (mg.kg $\left.\mathrm{kg}^{-1}\right)$ & 3.3 & Níquel (mg.kg-1) & 6.1 \\
\hline Bário $\left(\mathrm{mg} \cdot \mathrm{kg}^{-1}\right)$ & 260 & Selênio (mg.kg-1) & $<1.0$ \\
\hline Boro (mg.kg-1) & $<1.0$ & Zinco (mg.kg-1) & 316 \\
\hline
\end{tabular}




\begin{tabular}{|llll|} 
Cádmio $\left(\mathrm{mg} \cdot \mathrm{kg}^{-1}\right)$ & 0.6 & Potássio $\left(\mathrm{mg} \cdot \mathrm{kg}^{-1}\right)$ & 216 \\
Cálcio $\left(\mathrm{g} \cdot \mathrm{kg}^{-1}\right)$ & 6.1 & Sódio $\left(\mathrm{mg} \cdot \mathrm{kg}^{-1}\right)$ & 585 \\
Chumbo $\left(\mathrm{mg} \cdot \mathrm{kg}^{-1}\right)$ & 37.5 & & \\
\hline Paixão Filho et al. $(2014)$ & &
\end{tabular}

Fonte: Paixão Filho et al. (2014)

Abreu et al. (2017) analisaram as perspectivas de reciclagem agrícola do lodo de esgoto no Estado do Rio de Janeiro. 0 alto teor de nutrientes em vários lotes de lodo (Tabela 6) corrobora os resultados obtidos com Paixão Filho et al. (2014) na avaliação com variações estatísticas.

Tabela 6 - Nutrientes e matéria orgânica em mg.kg ${ }^{-1}$ presentes em lotes de lodo de esgoto nas Estações de Tratamentos de Esgoto na área metropolitana do Rio de Janeiro, RJ - Brasil.

\begin{tabular}{lllllllll}
\hline STS & Lote & N & P & K & Ca & Mg & M0 & pH \\
\hline Alegria & I & 38,83 & 6,16 & 5,00 & 2,36 & 0,15 & 544,1 & 5,5 \\
Alegria & II & 32,94 & 9,56 & 3,99 & 2,11 & 5,45 & 572,8 & 5,1 \\
Barra & III & 18,37 & 8,91 & 2,09 & 2,39 & 5,69 & 398,3 & 7,3 \\
Ilha & IV & 33,47 & 5,42 & 1,82 & 1,56 & 3,22 & 578,8 & 5,3 \\
Ilha & V & 28,78 & 5,22 & 1,57 & 1,74 & 3,22 & 589,4 & 5,0 \\
Ilha & VI & 14,24 & 5,53 & 4,01 & 18,51 & 5,83 & 598,7 & 6,5 \\
Sarapuí & VII & 42,33 & 17,23 & 2,73 & 1,35 & 2,95 & 515,9 & 6,3 \\
Sarapuí & VIII & 39,81 & 12,24 & 3,07 & 8,59 & 2,69 & 513,2 & 6,5 \\
\hline Média & - & 31,09 & 8,78 & 3,03 & 4,83 & 3,65 & 538,9 & 5,8 \\
Desvio Padrão & - & 10,17 & 4,24 & 1,21 & 6,01 & 1,93 & 65,3 & 0,9
\end{tabular}

N- método Kjedhal; P,Ca e Mg - Espectrometria de emissão óptica por plasma acoplado indutivamente; K método por fotometria de chama; MO - método Walkley e Black; pH - H2O.

Fonte: Abreu et al. (2017).

Anterior a um programa de reciclagem, é fundamental o conhecimento sobre a composição do material, análise química para quantificar e identificar metais, matéria orgânica, macro e micronutrientes presentes, definir um processo de desinfecção que atenda a legislação e uma demanda regional, para justificar a alternativa (ABREU et al., 2017; NOBREGA et al., 2017).

\section{Cultivo de Mudas Nativas com Biossólidos de Lodo de ETE e Resíduos Orgânicos}

A remediação de danos ocasionados pelas atividades humanas estimula a elaboração de projetos que objetivem recuperar e/ou preservarem biomas e suas características naturais. Com a ampla diversidade edafoclimática do Brasil, são necessários estudos avaliando o desempenho do lodo nas diferentes situações do uso do lodo, de forma a estimular seus benefícios em solos degradados (NOBREGA et al., 2017; SIQUEIRA et al., 2017). 
Lodo de estação de tratamento de esgoto (ETE) e compostagem orgânica em cultivo de mudas nativas: estudo na região dos lagos, RJ - Brasil

Bonini et al. (2015) estudaram a recuperação de um Latossolo Vermelho degradado na construção da Usina Hidroelétrica de Ilha Solteira-SP, utilizando-se de lodo de esgoto e adubação mineral. Os resultados obtidos mostraram que o lodo de esgoto influenciou positivamente os atributos químicos dos solos estudados em relação ao pH, capacidade de troca catiônica do solo, matéria orgânica, soma de bases, nutrientes e a dose de $60 \mathrm{mg} . \mathrm{kg}^{-1} \mathrm{de}$ lodo de esgoto foi o tratamento com melhor resultado pelo incremento de matéria orgânica e bases trocáveis do solo.

Importantes vantagens na disposição agrícola do lodo de esgoto voltada para o setor florestal são a característica de bioacumulação de metais pesados em sua biomassa e a não destinação ao consumo humano. Por essa razão, cresce a utilização de diversos resíduos na produção de mudas florestais (CALDEIRA et al., 2014), e as técnicas que permitem o uso do lodo de esgoto na produção de mudas nativas contribui com a restauração ambiental (NOBREGA et al., 2017).

Nobrega et al. (2017) salientam que os conhecimentos a respeito dos efeitos sobre o desenvolvimento de espécies nativas são insuficientes, e destaca a necessidade de estudos que contribuam com metodologias para seu reúso. Silva et al. (2015) avaliaram a produção de mudas de juçara com resíduos agroindustriais e lodo de esgoto compostado, e não verificaram sintomas de toxidez nas plantas e não houve sintoma de deficiência nutricional.

Caldeira et al. (2014) utilizaram lodo de esgoto e resíduos orgânicos na composição de substrato para a produção de mudas de Eucalyptus grandis Hill ex Maiden. As mudas com 80\% de lodo + 20\% de palha de café apresentaram os maiores resultados, sendo a composição mais indicada para a produção entre as demais. No trabalho de Trigueiro e Guerrini (2014), o lodo de esgoto foi utilizado na produção de mudas de aroeira-pimenteira (Schinus terebinthifolius Raddi.), e a proporção ideal indicada pelos autores deve situar-se entre 40 e 60\%, com casca de arroz carbonizada.

Afaz et al. (2017) avaliaram a viabilidade do lodo, proveniente de estação de tratamento de esgoto, como fertilizante alternativo para o cultivo inicial de eucalipto e o resultado obtido mostrou que o lodo possui potencial para substituir fertilizantes minerais convencionais no cultivo inicial de eucalipto.

\section{Estação de Tratamento de Esgoto de Araruama - RJ}

Em Araruama está localizada a maior estação ecológica de esgotos da América Latina, na região dos Lagos, no Rio de Janeiro. A ETE Ponte dos Leites possui uma capacidade de 
tratamento de $200 \mathrm{~L} / \mathrm{s}$ e atende a região central do município. Os processos de tratamento do esgoto não utilizam energia elétrica, não adicionam produtos químicos para tratar a matéria orgânica, apenas plantas que promovem o tratamento terciário. Previamente, as estações elevatórias realizam um tratamento primário de gradeamento grosso e na chegada da estação, o esgoto passa por uma caixa de areia e um gradeamento fino.

0 esgoto segue para uma lagoa de aeração e sedimentação, com a presença de aguapés (Eichhornia crassipes), que iniciam a retirada de nitrogênio e fósforo do esgoto de modo superficial com o alcance de suas raízes. Os aguapés são manejados conforme seu crescimento e manutenção da eficiência do tratamento, além de serem limitadas por ilhas móveis.

Após a lagoa de aeração e sedimentação, o efluente segue para outra lagoa com presença de salvinia (Salvinia auriculata). Originária do pantanal, sua função consiste na retirada da matéria orgânica, além do fósforo e nitrogênio, de forma superficial nas zonas de raízes (Figura 1.). É indispensável o manejo correto para manutenção da lagoa e a proliferação controlada da planta para melhor eficiência no tratamento. A salvinia não é nativa da Região dos Lagos, por isso é imprescindível manter um berçário para estas plantas, devido sua importância.

Fonte: A autora, 2018.

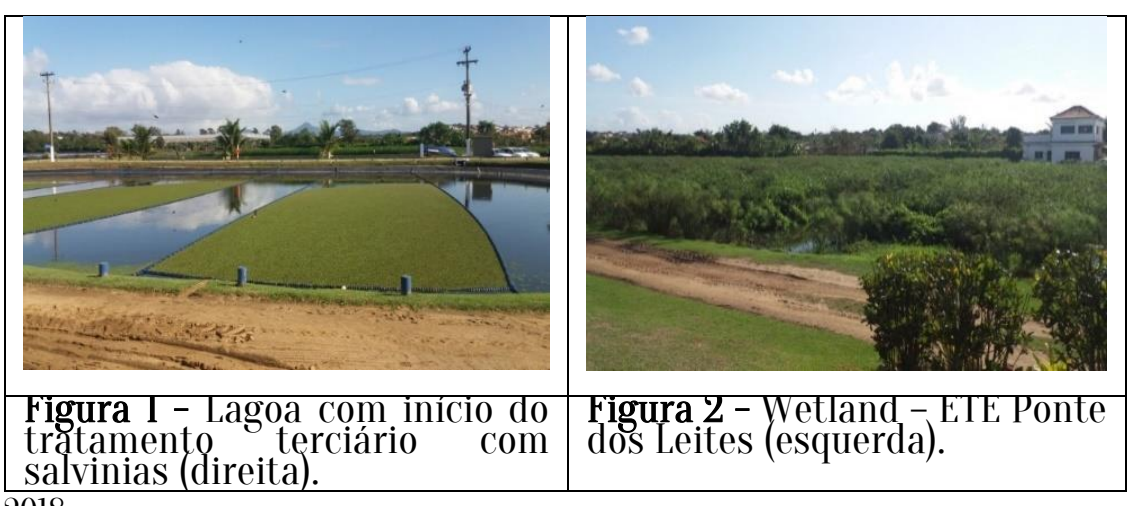

A área de Wetlands é composta por uma área delimitada em sua borda por papiros (Cyperus papyrus) e o plantio de papirinho (Cyperus prolifer) - nativa do Egito, Bacia do Rio Nilo e sombrinha chinesa (Cyperus alternifolius) - norte da África, em taludes formando corredores para a circulação do efluente, e em seu continuo crescimento, demanda manejo de podas (Figura 2).

Ao final do tratamento terciário, o efluente atende todas as exigências da legislação para o lançamento em corpos hídricos, porém ainda percorre pela Wetland Nativa, composta por plantas que estavam no local anteriormente à implantação da ETE ecológica, de modo a aumentar a eficiência do tratamento. 
Lodo de estação de tratamento de esgoto (ETE) e compostagem orgânica em cultivo de mudas nativas: estudo na região dos lagos, RJ - Brasil

Ressalta-se que o tratamento é satisfatório comparado a estações convencionais, uma vez que não há utilização de produtos químicos e a inexistência de odor. A economia da ETE Ponte dos Leites em relação a uma ETE convencional com a mesma capacidade aproxima-se a 75\%. Salienta-se que a instalação de uma ETE ecológica necessita de uma área considerável, de modo a depender do volume de tratamento, comparada a ETE convencional, isto é, a disponibilidade de área pode ser um fator limitante.

0 custo de instalação pode ser rapidamente diluído, pelo fato do baixo custo de manutenção da ETE, pela economia de produtos químicos (Figura 3) que não são necessários, e consumo de energia elétrica (Figura 4), todos os custos fixos de uma ETE convencional que elevam o custo total do tratamento.

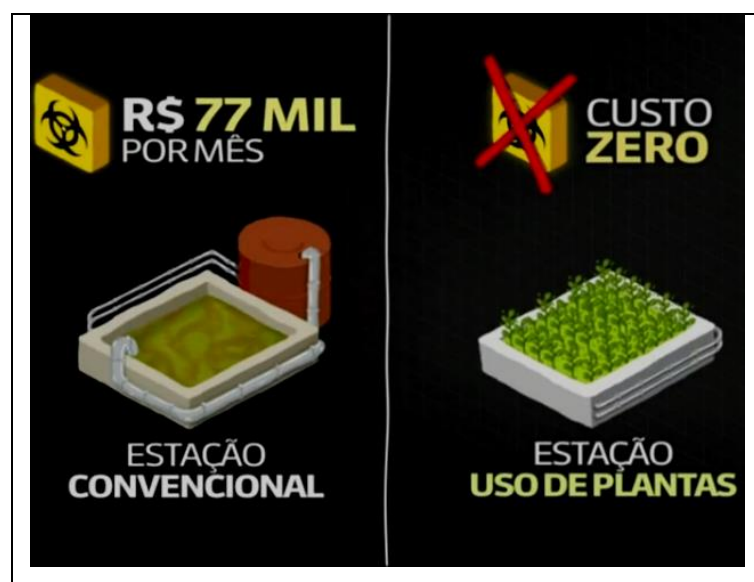

Figura 3 - Economia de produtos químicos na manutenção de uma ETE ecológica.

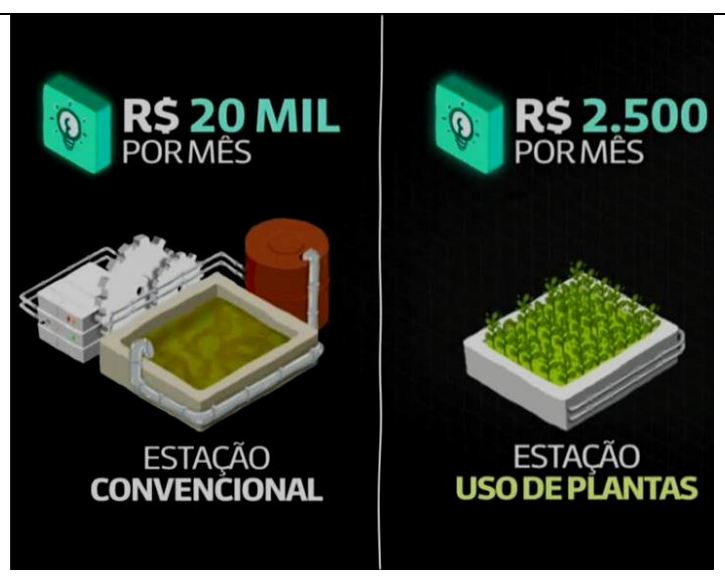

Figura 4 - Economia de energia na manutenção de uma ETE ecológica.

Fonte: GloboNews, 2014.

Todo o resíduo de poda e o lodo de esgoto decorrente do tratamento são levados ao pátio de compostagem, e há produção de um substrato de alta qualidade. Por mês são processados aproximadamente 45 toneladas de plantas e 10 toneladas de lodo por semana. 0 custo do transporte desses resíduos para o aterro seria de aproximadamente $\mathrm{R} \$ 16.000,00$ reais por mês, entretanto, a ETE destina o substrato para uma empresa de produção de mudas florestais e plantas utilizadas em paisagismo.

\section{Uso de substrato de lodo de esgoto em espécies arbóreas da Região dos Lagos}

Nos últimos anos, no estado do Rio de Janeiro, ocorre grande demanda por plantios visando restauração florestal e, consequentemente, por mudas de espécies nativas da Mata 
Atlântica (ALONSO et al., 2014). Para avaliar a potencialidade do lodo de esgoto em mudas da Mata Atlântica, deve-se estudar o comportamento dessas espécies em cada região.

As várias unidades geomorfológicas do estado proporcionam uma diversidade de paisagens e riqueza de espécies, incluindo várias endêmicas. Com isso, existem lacunas no conhecimento de algumas espécies que não são incluídas em projetos de restauração florestal (COELHO et al., 2017; ALONSO et al., 2014).

A aplicação biossólidos pode potencialmente restaurar propriedades do solo mais rápido do que os processos ecossistêmicos naturais ao longo do tempo (SAMPAI0 et al., 2016). É vital a recomposição de ecossistemas degradados, e isso exige a identificação das espécies, pesquisa sobre o substrato para a germinação, quebra de dormência de sementes, manejo e adaptação da espécie em seu local final.

Para o lodo, o fator decisivo em seu emprego são os metais. Com isso, é importante a utilização de espécies que absorvem metais com a finalidade de prevenir o impacto desses elementos no ambiente. Sampaio et al. (2016) afirma que as espécies, capixingui (Croton floribundus Spreng.), aroeira-pimenteria (Schinus terebinthifolius Raddi), canafístula (Peltophorum dubium Spreng.), cedro-rosa (Cedrela fissilis Vell.), mutamba (Guazuma ulmifolia Lam.) e angico-vermelho (Anadenanthera macrocarpa Benth.), copaíba (Copaifera langsdorffii Desf.), jatobá (Hymenaea courbaril L.) e jequitibá (Cariniana estrellensis Raddi.), não apresentaram efeito significativo sobre as concentrações de metais no solo com a aplicação do biossólido.

\section{CONCLUSÃO}

Nesse estudo conclui-se que com a verificação de experiências bem-sucedidas em todo o país, pode-se promover o emprego do biossólido na Região dos Lagos, uma vez que existe todo um potencial para aproveitamento do composto, pela quantidade de ETEs espalhadas por toda a região, volume do composto que é produzido e as várias alternativas viáveis.

Recomenda-se o emprego do lodo em espécies nativas, em virtude da importância da recuperação de áreas degradadas e recuperação de recursos naturais, o que atualmente é o recomendado para o estado do Rio de Janeiro. Pode-se ter também um ganho ambiental com o cultivo de espécies nativas com potenciais diversos e a fertilização dos solos. 
Lodo de estação de tratamento de esgoto (ETE) e compostagem orgânica em cultivo de mudas nativas: estudo na região dos lagos, RJ - Brasil

Com a visita técnica na ETE ecológica de Araruama - RJ foi possível constatar a possibilidade de obtenção de um efluente com qualidade igual a muitas ETEs convencionais, com um custo de manutenção menor além do ganho ambiental incorporado.

Por fim, conclui-se que a viabilidade na utilização do lodo de esgoto como insumo para produção de composto orgânico com a finalidade de produção de mudas nativas e recuperação de solos. Para sucesso nos processos de germinação e desenvolvimento das plantas recomendam-se pesquisas com as espécies da Mata Atlântica para determinar qual a melhor concentração do lodo, pelo fato de que cada espécie possui um comportamento perante o biossólido.

\section{REFERÊNCIAS BIBLIOGRÁFICAS}

ABREU, A. H. M. et al. Characterization of sewage sludge generated in Rio de Janeiro, Brazil, and perspectives for agricultural recycling. Semina: Ciências Agrárias, Londrina, v.38, n. 4, suplemento 1, p. 2433-2448, 2017. Disponível em: <http://www.uel.br/revistas/uel/index.php/se

magrarias/article/view/27675>. Acesso em: 02 jul. 2018.

AFAZ, D. C. S.; BERTOLAZI, K. B.; VIANI, R. A. G.; SOUZA, C. F. Composto de lodo de esgoto para o cultivo inicial de eucalipto. Ambiente \& Água - An Interdisciplinary Journal of Applied Science, vol.12, num. 1, jan - fev, 2017, pp.112123. Disponível em: <http://www.scielo.br/scielo.php?frbrVersion=5\&script=sci_arttext\&pid=S1980993X2017000100112 \&lng=enôtlng=en>. Acesso em: 30 jun. 2018.

AGÊNCIA NACIONAL DE ÁGUAS (ANA) - MINISTÉRIO DAS CIDADES. ATLAS ESGOTOS Despoluição de Bacias Hidrográficas. Relatório de esgotamento sanitário municipal, BRASIL - 2017. Disponível em: 〈http://www.snirh.gov.br/portal/snirh/snirh-1/atlas-esgotos . Acesso em: 28 jun. 2018.

ÁGUAS de Juturnaíba: Estação de tratamento de esgoto. 2018. Disponível em: <https://www.grupoaguasdobrasil.com.br/aguas-juturnaiba/agua-e-esgoto/estacao-de-tratament o-deesgoto/>. Acesso em: 30 jun. 2018.

ALONSO, J. M. et al. Avaliação da diversidade de espécies nativas produzidas nos viveiros florestais do estado do Rio de Janeiro. Revista Floresta, Curitiba, PR, v. 44, n. 3, p. 369 - 380, jul. / set. 2014. Disponível em: $<$ https://revistas.ufpr.br/floresta/artic le/view/31910/23186>. Acesso em: 28 jun. 2018.

ASSOCIAÇÃO BRASILEIRA DE NORMAS TÉCNICAS. NBR 10.004 - Resíduos sólidos: classificação. Rio de Janeiro: ABNT, 2004. Disponível em: <http://analiticaqmcresiduos.paginas

.ufsc.br/files/2014/07/Nbr-10004-2004-Classificacao-De-Residuos-Solidos.pdf〉. Acesso em: 01 jul. 2018.

AVILA, J. V.; et al. Essential oil production of lemongrass (Cymbopogon citratus) under organic compost containing sewage sludge. Revista Brasileira de Engenharia Agrícola e Ambiental v.20, n.9, p.811-816, 2016. Disponível em: $<$ http://www.scielo.br/scielo.php?script=sci_arttext\&p id=S1415-4366201600090081l>. Acesso em: 29 jun. 2018.

BONINI, C. S. B; ALVES, M.C; MONTANARI, R. Lodo de esgoto e adubação mineral na recuperação de atributos químicos de solo degradado. Revista Brasileira de Engenharia Agrícola e Ambiental v. 19, nº 4, p. 388-393, 2015. Disponível em: $<$ https://repositorio.unesp.b r/handle/11449/128266>. Acesso em: 27 jun. 2018.

BRASIL. Lei Federal $\mathrm{n}^{\mathbf{0}}$ 6.894, de 16 de dezembro de 1980. Poder Executivo, Brasília, DF. 1980. Disponível em: <http://www.planalto.gov.br/ccivil_03/LEIS/1980-1988/L6894.htm〉. Acesso em: 29 jun. 2018. 
. Instrução Normativa $\mathbf{n}^{0}$ 27, de 5 de junho de 2006. Poder Executivo, Brasília, DF. 2006a. Disponível em: $<\mathrm{http}$ //www.agricultura.gov.br/assuntos/insumos-agropecuarios/insumos agricolas/fertilizantes/legislacao/in-sda-27-de-05-06-2006-alterada-pela-in-sda-07-de-12-4-16-republicadaem-2-5-16.pdf`. Acesso em: 29 jun. 2018.

. Ministério da Agricultura, Pecuária e Abastecimento. Instrução Normativa $\mathrm{n}^{0}$ 35, de 4 de julho de 2006. Poder Executivo, Brasília, DF. 2006b. Disponível em: <http://www.agricultura.gov.br/assuntos/insumosagropecuarios/insumos-agricolas/fertilizantes /legislacao/in-35-de-4-7-2006 corretivos.pdf>. Acesso em: 29 jun. 2018.

. Ministério do Meio Ambiente. Conselho Nacional do Meio Ambiente. Resolução CONAMA n.375, de 29 de agosto de 2006. Diário Oficial [da] República Federativa do Brasil, Brasília, DF, 30 ago. 2006c. Disponível em: <http://www2.mma.gov.br/port/conama/res/ res06/res37506.pdf>. Acesso em: 29 jun. 2018.

. Presidência da República Casa Civil. Subchefia para Assuntos Jurídicos. Lei $\mathbf{n}^{0}$ 12.305, de 2 de agosto de 2010. Diário Oficial [da] República Federativa do Brasil, Brasília, DF, 03 ago. 2010. Disponível em: <http://www.planalto.gov.br/ccivil_03/_Ato2007-2010/2010/Lei/L12305.htm〉. Acesso em: 29 jun. 2018.

CALDEIRA, M. V. W; et al. Crescimento de mudas de Eucalyptus grandis utilizando Lodo de esgoto, fibra de coco e palha de café in natura. FLORESTA, Curitiba, PR, v. 44, n. 2, p. 195 - 206. abr/jun. 2014. Disponível em: <https://revistas.ufpr.br/floresta/article/view/30170〉. Acesso em: 27 jun. 2018.

CAMAR60, F. P.; et al. Removal of Toxic Metals from Sewage Sludge Through Chemical, Physical, and Biological Treatments - a Review. Water Air Soil Pollut p. 227 - 433 (2016). Disponível em: <https://link-springercom.ezl35.periodicos.capes.gov.br/article/10.1007/s11270

-016-3141-3>. Acesso em: 01 jul. 2018.

CAMARG0, R.; MALDONADO, A. C. D.; DIAS, P. A. S; SOUZA, M. F.; FRANÇA, M. S. Diagnose foliar em mudas de pinhãomanso (Jatropha Curcas L.) produzidas com biossólido. Revista Brasileira de Engenharia Agrícola e Ambiental. V. 17, n. $\quad 3, \quad$ p. $\quad 283-290, \quad 2013.20$ Disponível $<\mathrm{http} / /$ www.scielo.br/scielo.php?frbrVersion=48sscript=sci_arttext\&pid=S141543 662013000300006 \&lng=enftlng=en>. Acesso em: 27 jun. 2018.

COELHO, M. A. N.; et al. Flora do estado do Rio de Janeiro: avanços no conhecimento da diversidade (Flora of Rio de Janeiro state: an overview of Atlantic Forest diversity). Rodriguésia 68(1): 001-011. 2017. Disponível em: 〈http://www.scielo.br/pdf/rod/v68nl/2175-7860-rod-68-01-0001.pdf〉. Acesso em: 29 jun. 2018.

DOMINGUEZ, D. X. Avaliação dos riscos ambientais associados à utilização agrícola do lodo de esgoto como condicionador e fertilizante de solo. Tese (Doutorado em Ciência Ambiental) - Programa de Pós-Graduação em Ciência Ambiental - Instituto de Energia e Ambiente da Universidade de São Paulo - SP. 2014. 116f. Disponível em: <http://www.teses.usp.br/teses/disponiveis/106/106132/tde-21122017105752/en.php〉. Acesso em: 29 jun. 2018.

FIJALKOWSKI, K.; et al. The presence of contaminations in sewage sludge - The current situation. Journal of $\begin{array}{llllllllll}\text { Environmental Management } & \mathrm{n}^{0} & 203 & \mathrm{p} .1126 & - & 1136 & \text { (2017). Disponível em: }\end{array}$ 〈https://www.sciencedirect.ezl35.periodicos.capes.gov.br/science/article/pii/S0301479717 305418?via\%3Dihub>. Acesso em: 29 jun. 2018.

GLOBONEWS. Cidades e Soluções. Brasil trata menos da metade do esgoto que gera. 30. Abr. 2018. 21min. Disponivel em: <https://globosatplay.globo.com/globonews/v/6701890/>. Acesso em: 26 mai. 2018.

GRANDO, R. L.; et al. Technology overview of biogas production in anaerobic digestion plants: A European evaluation of research and development. Renewable and Sustainable Energy Reviews 80 p. 44-53 (2017). Disponivel em: 〈https://www.sciencedirect.com/science/article/pii

/S1364032117307074〉. Acesso em: 02 jul. 2018.

KACPRZAK, M.; et al. Sewage sludge disposal strategies for sustainable development. Environmental Research $\mathrm{n}^{\circ}$ 156 p. 39-46 (2017). Disponível em: <https://www.sciencedirect. ez135.periodicos.capes.gov.br/science/article/pii/S0013935117304322>. Acesso em: 01 jul. 2018. 
Lodo de estação de tratamento de esgoto (ETE) e compostagem orgânica em cultivo de mudas nativas: estudo na região dos lagos, RJ - Brasil

LEITE, T. A. Compostagem Termofílica de Lodo de Esgoto: Higienização e Produção de Biossólido para uso Agrícola. Dissertação (Mestrado) - Faculdade de Saúde Pública da Universidade de São Paulo, SP. 2015. 186p. Disponível em: <http://www.teses.usp.br/teses/dis poniveis/6/6139/tde-02122015-142451/pt-br.php>. Acesso em: 30 jun. 2018.

LOMBARDI, L.; et al. Environmental comparison of alternative treatments for sewage sludge: An Italian case study. Waste Management $\quad \mathrm{n}^{\circ} \quad 69 \quad$ p. 365-376 $\quad$ (2017). Disponível em: <https://www.sciencedirect.com/science/article/pii/S0956053X17306189?via\%3Dihub〉. Acesso em: 29 jun. 2018.

LOUSADA, L. L. Nutrição e crescimento de sorgo sacarino e alterações nos atributos do solo pela aplicação de lodo de esgoto doméstico. Tese (Doutorado em Produção Vegetal) - Universidade Estadual do Norte Fluminense, Campos/RJ, 2015. 108f. Disponivel em: <http://uenf.br/posgraduacao/produca0-vegetal/wpcontent/uploads/sites/10/2015/11/Tese-Lidia

ne-de-Lima-Lousada-vers\%C3\%A30-impressa.pdf>. Acesso em: 02 jul. 2018.

LIU, H. T. Achilles heel of environmental risk from recycling of sludge to soil - As amendment: a summary in recent ten years (2007-2016). Waste management $\mathrm{n}^{0} \quad 56$ p. 575-583 (2016). Disponível em: <https://www.sciencedirect.ezl35.periodicos.capes.gov.br/science/article/pii/S0

95605X16302604?via\%3Dihub>. Acesso em: 30 jun. 2018.

MORETTI, S. M. L; BERTONCINI, E. I; ABREU JUNIOR, C. H. Decomposição de lodo de esgoto e composto de Lodo de esgoto em nitossolo háplico. Revista Brasileira de Ciências do Solo, ${ }^{\circ} 39$ p.1796-1805, 2015. Disponível em: 〈http://www.scielo.br/pdf/rbcs/v39n6/0100-0683-rbcs-39-6-1796.pdf>. Acesso em: 29 jun. 2018.

NOBREGA, M. A. D. S.; PONTES, M. D. S.; SANTIAGO, E. F. Incorporação do lodo de esgoto na composição de substrato para produção de mudas nativas. Acta Biomedica Brasiliensia - v.8, n. 1. p: 43 - 55. Jul - 2017. Disponível em: <http://www.actabiomedica.com.br/index.php/ac ta/article/view/164>. Acesso em: 27 jun. 2018.

PAIXÃo FILHO, J. L. D.; GABRIELLI, G.; CORAUCCI FILHO, B.; TONETTI. A. L. Use of stabilization pond sludge in cultivation of roses. Revista Brasileira de Engenharia Agrícola e Ambiental v.18 nº 1, p. 85-89, 2014.

PATHAK, A.; DASTIDAR, M. G.; SREEKRISHNAN, T. R. Bioleaching of heavy metals from sewage: a review. Journal of Environmental Management, 90, 2343-2353. (2009). In: CAMARG0, F. P.; et al. Removal of Toxic Metals from Sewage Sludge Through Chemical, Physical, and Biological Treatments - a Review. Water Air Soil Pollut p. 227 433 (2016). Disponível em: <https://link-springer-com.ezl35.periodicos.capes.gov.br/article/10.1007/s11270 -016-3141-3>. Acesso em: 30 jun. 2018.

PROLAGOS: Sistemas de coleta e tratamento de esgoto. 2018. Disponível em: 〈http://www.prolagos.com.br/sistemas-de-coleta-e-tratamento-de-esgoto/〉. Acesso em: 02 jul. 2018.

ROSSMANN, M; et al. Redução da Viabilidade de ovos de helmintos em Lodo de esgoto domestico caleado. Engenharia na agricultura, Viçosa - MG, V.22 N.1, Jan/ Fev, p. 43 - 49, 2014. Disponível em: 〈http://www.locus.ufv.br/handle/123456789/20284〉. Acesso em: 28 jun. 2018.

SAMPAI0, Américo de Oliveira. Afinal, Queremos ou não Viabilizar o Uso Agrícola do Lodo Produzido em Estações de Esgoto Sanitário? Uma Avaliação Crítica da Resolução CONAMA 375. Revista DAE nº 193. Ano 2013.

SAMPAIO, T. F.; et al. The Impact of Biosolid Application on Soil and Native Plants in a Degraded Brazilian Atlantic Rainforest Soil. Water Air Soil Pollut (2016) 227: 1. Disponível em: <https://link-springercom.ez135.periodicos.capes.gov.br/article/10.1007/s11270-015-2689-7>. Acesso em: 30 jun. 2018.

SILVA, F. A. M; et al. Produção de mudas de juçara com resíduos agroindustriais e lodo de esgoto compostados. Brazilian Journal of Biosystems Engineering, v. 9, p. 109-121, 2015. Disponível em: 〈http://seer.tupa.unesp.br/index.php/BIOENG/article/view/259>.Acesso em: 30 jun. 2018.

SIQUEIRA, D. P.; BARROSO, D. G.; MARCIANO, C. R. Sewage sludge: guidelines and its use as fertilizer, soil conditioner and forest substrate - Lodo de esgoto: diretrizes e o seu uso como fertilizante, condicionador de solo 
e substrato florestal. VÉRTICES, Campos dos Goytacazes/RJ, v.19, n.3, p. 171-186, set./dez. 2017. Disponível em: $\langle$ http://essentiaeditora.iff.edu.br/index.php/vertices/article/view/7587〉. Acesso em: 27 jun. 2018.

SYED S. A.; et al. Thermochemical processing of sewage sludge to energy and fuel: Fundamentals, challenges and considerations. Renewable and Sustainable Energy Reviews 80 (888-913), 2017. Disponível em: <https://wwwsciencedirect.ezl35.periodicos.capes.gov.br/

science/article/pii/S1364032117309036?via\%3Dihub>. Acesso em: 02 jul. 2018.

TRIGUEIR0, R. M.; GUERRINI, I. A. Utilização de lodo de esgoto na produção de mudas de aroeira-pimenteira. Revista árvore, Viçosa/MG, v. 38, n. 4, p. 657-665, 2014. Disponível em: $<\mathrm{http}$ //www.scielo.br/scielo.php?frbrVersion=3\&script=sci_arttext\&pid=S010067622014000400009\&lng=en\&tlng= en>. Acesso em: 30 jun. 2018. 